\title{
A FORMAÇÃO DE UMA NOVA IDENTIDADE A PARTIR DA RETERRITORIALIZAÇÃO CAMPESINA: trabalhadores urbanos em assentamentos rurais na Campanha Gaúcha
}

\section{THE FORMATION OF A NEW IDENTITY FROM THE PEASANT RETERRITORIALIZATION: urban workers in rural settlements in Campanha Gaúcha}

\author{
Michele Lindner \\ Bolsista PDJ - CNPq - Membro do NEAG/UFRGS \\ michelindner@gmail.com \\ Joel Luís Melchiors \\ NEAG - UFRGS \\ joelmelchiors@yahoo.com.br \\ Rosa Maria Vieira Medeiros \\ Professora do Departamento de Geografia - Membro do NEAG/UFRGS \\ rmvmedeiros@yahoo.com.br
}

RESUMO

A questão agrária e o acesso a terra envolvem uma gama variada de temáticas. A luta pelo acesso a terra no Brasil já é uma questão histórica e vem ganhando cada dia mais força através da organização dos movimentos sociais. Nas ultimas décadas é possível identificar também a crescente participação de trabalhadores oriundos de espaços urbanos em movimentos de luta pela terra e em assentamentos rurais. Trata-se se uma reação frente a pobreza e falta de empregos urbanos, que fazem com que estes busquem novos locais de moradia e trabalho em atividades agrícolas e não agrícolas como forma de garantir a sobrevivência. Essas mudanças territoriais não se limitam apenas as ocupações e formas de geração de renda desses indivíduos. Um território é antes de tudo um espaço de vida, um espaço apropriado por um indivíduo ou um grupo de indivíduos. Trata-se de um local de trabalho, um local de luta pela sobrevivência, onde se constrói os mais diversos laços e relações sociais, um espaço de vida. Nesse sentido o presente estudo aborda a formação de uma nova identidade de antigos trabalhadores urbanos a partir da desterritorialização e subsequente reterritorialização campesina de assentados na Campanha Gaúcha no estado do Rio Grande do Sul.

Geo UERJ - Ano 15, no . 24, v. 1, $1^{\circ}$ semestre de 2013 p. 145-160

ISSN: $1415-7543$ E-ISSN: 1981-9021

http://www.e-publicacoes.uerj.br/index.php/geouerj 
Palavras-chave: Territórios, rural-urbano, espaços de vida, trabalhadores urbanos, assentamentos.

\section{ABSTRACT}

The agrarian issue and access to land involve a wide range of topics. The struggle for land in Brazil is already a historical issue and is gaining more strength every day through the organization of social movements. In recent decades is also possible to identify the growing participation of workers from urban areas in movements in the struggle for land and in rural settlements. It is a reaction to poverty and the lack of urban work, which make these pursue new places to reside and work in agricultural and nonagricultural activities as a way to ensure survival. These territorial changes are not limited to occupations and ways of generating income of these individuals. A territory is above all a living space, a suitable space for an individual or a group of individuals. This is a workplace, a place of struggle for survival, where it builds the most diverse ties and social relations, a living space. In this sense the present study addresses the formation of a new urban identity of former workers from the desterritorialization and subsequent reterritorialization peasant settlers in Campanha Gaúcha in the state of Rio Grande do Sul.

Keywords: territories, rural-urban, living spaces, urban workers, settlements.

\section{INTRODUÇÃO}

A temática do artigo aqui apresentado vem explorar a presença de trabalhadores urbanos, em assentamentos rurais. Há algum tempo, já se percebe o aumento da presença de pessoas de procedência urbana no Movimento dos Trabalhadores Rurais Sem Terra (MST), que "expulsos" das cidades, tentando fugir da pobreza urbana, buscam no Movimento uma alternativa para a melhoria de vida.

Entre as diversas causas de agravamento da pobreza urbana, podemos nos remeter a modernização da agricultura, que em determinado momento "expulsou" trabalhadores do campo, os quais buscaram abrigo e empregos nas cidades, multiplicando os cinturões de pobreza nesses espaços.

Medeiros (2007), ao falar da identidade camponesa, explica que no Rio Grande do Sul, os colonos que ali chegaram, ocuparam locais considerados vazios pelo governo. Nesses locais muitas vezes isolados, os colonos buscaram reproduzir seus hábitos culturais, procurando reconstruir a sua identidade no novo espaço. E assim eles desbravaram

Geo UERJ - Ano 15, n⿳. 24, v. 1, $1^{\circ}$ semestre de 2013 p. 145-160

ISSN: 1415-7543 E-ISSN: 1981-9021

http://www.e-publicacoes.uerj.br/index.php/geouerj 
terras, construíram cidades, desenvolveram regiões e "não desistiram quando a modernização da agricultura chegou ao planalto gaúcho e a soja ocupou seus espaços de sobrevivência” (MEDEIROS, 2004, p. 147). Como alternativas, partiram para áreas distantes ou foram atraídos para as cidades, "mas houve aqueles que ficaram e que não desistiram diante da dificuldade, diante da luta pelo direito a ter acesso à terra. Eles se organizaram, reivindicaram, resistiram e venceram. Eles criaram o Movimento dos Agricultores Sem Terra" (MEDEIROS, 2004, p. 147).

Contudo, nos dias atuais, a luta pelo acesso a terra não é mais apenas daqueles que persistiram, mas também daqueles que foram atraídos as cidades e depois rejeitados, de seus filhos, de seus netos, daqueles que retornam ao campo pelo mesmo motivo que o deixaram. A formação de uma nova identidade a partir da reterritorialização campesina, nada mais é do que o retorno a um antigo território. Nesse sentido, o presente artigo busca demonstrar os resultados de pesquisas de campo em assentamentos em três cidades da Campanha Gaúcha: Santa Margarida do Sul, São Gabriel e Santana do Livramento. As informações aqui apresentadas tiveram como objetivo identificar a presença de trabalhadores oriundos de áreas urbanas nos assentamentos rurais, seus sucessivos processos de desterritorialização-reterritorialização e a recriação de seus "espaços de vida", por meio da apresentação de informações referentes à situação anterior, as motivações para a entrada no Movimento e na luta pela terra e as principais mudanças após as transferências para os assentamentos.

\section{O MOVIMENTO DOS TRABALHADORES SEM TERRA (MST): DESTERRITORIALIZAÇÃO E RETERRITORIALIZAÇÃO}

\footnotetext{
"Os lugares e os momentos formam a realidade. As pessoas fazem os momentos, transformam os lugares e constroem a realidade" (FERNANDES, 2000, p. 50).
}

A citação que dá início a seção traduz perfeitamente os processos de desterritorialização e reterritorialização e demonstra o quanto o Movimento dos Trabalhadores Rurais Sem Terra (MST), encontra-se constantemente ligado a estes processos.

A luta pela terra significa a luta pelo território, uma luta que visa a reterritorialização de indivíduos que em determinado momento, devido a circunstâncias diversas, foram 
expropriados de seus antigos territórios. Nesse sentido, ao pensarmos o território, pensamos no espaço de forma política, social e culturalmente.

Para Raffestin (2011), o espaço e o território são diferentes, o espaço é anterior ao território, o território se forma a partir do espaço, dessa forma, ao "se apropriar do espaço, concreta ou abstratamente (por exemplo pela representação), o ator 'territorializa' o espaço" (RAFFESTIN, 2011, p.128). Assim, a territorialidade reflete a multidimensionalidade do "vivido" pelas sociedades e esse processo, o processo territorial, se dá por intermédio de um sistema de relações existenciais e/ou produtivistas, que por se tratarem de relações com a natureza e relações sociais, tratamse de relações de poder (RAFFESTIN, 2011).

Dessa forma, torna-se claro que um território representa para o indivíduo que nele habita o seu "espaço de vida", espaço esse onde ocorrem as relações entre os indivíduos nas diversas escalas. Trata-se do local onde se luta pela sobrevivência, se mantém relações políticas, sociais e culturais, o espaço onde se vive, onde se cria identidade.

Nesse contexto, Saquet (2009, p. 212), coloca que “o território é produzido com o passar dos dias, meses, anos, décadas, através de relações sociais incessantes que se estabelecem, com influências, interferências, dominações e domínios, imprimindo marcas no seu interior (do território)". Essas marcas, são marcas culturais dos que ali habitam, representam o cotidiano e a história dos que ali chegaram, se instalaram, se territorializaram, criando sua identidade em seus espaços de vida.

Da mesma forma, Haesbaert (2004, p. 95-96), explica que "o território, enquanto relação de dominação e apropriação sociedade-espaço, desdobra-se ao longo de um continuum que vai da dominação político-econômica mais 'concreta' e 'funcional' à apropriação mais subjetiva e/ou "cultural-simbólica".

Dessa forma, territorializar-se:

\footnotetext{
“significa criar mediações espaciais que nos proporcionem efetivo 'poder' sobre nossa reprodução enquanto grupos sociais (para alguns também enquanto indivíduos), poder este que é sempre multiescalar e multidimensional, material e imaterial, de 'dominação' e 'apropriação' ao mesmo tempo" (HAESBAERT, 2004, p. 97)
}

A dominação ou apropriação de um determinado território pode não ser permanente. Muitas vezes as territorialidades estão em movimento, a esse movimento nos referimos 
ao processo de desterritorialização e sua conseqüência a reterritorialização. Simploriamente a desterritorialização refere-se ao movimento pelo qual se abandona o território e a reterritorialização o movimento de construção do território (DELEUZE e GUATTARI, 1997b apud HAESBAERT, 2004). Portanto, trata-se de um processo consecutivo, toda desterritorialização implicará em uma reterritorialização.

\begin{abstract}
"No movimento, simultaneamente à desterritorialização dá-se a reterritorialização. São processos intimamente ligados na mobilidade de força de trabalho. No primeiro, há a perda do território inicialmente apropriado e reconstruído, [...] e no segundo, uma reprodução de elementos do território anterior, em algumas de suas características. O velho é recriado no novo, num movimento concomitante de descontinuidade e continuidade, de superações. Os processos de territorialização-desterritorialização-reterritorialização (TD-R) não estão desligados: condicionam-se mutuamente. A territorialização está na desterritorialização, e vice-versa; concomitantes e articuladas" (SAQUET, 2009, p. 214).
\end{abstract}

Nesse sentido, ao analisarmos o histórico da luta pela terra e conseqüente formação do MST, percebemos claramente que sua formação se deu impulsionada por processos de desterritorialização e pela constante busca da reterritorialização. Nesse sentido, Fernandes (2000, p. 19) salienta que o "sentido da formação do Movimento dos Trabalhadores Rurais Sem Terra está na sua espacialização e territorialização, porque traz o significado da resistência por meio da sua recriação".

Contudo, para compreender o processo de desterritorialização e formação da identidade do MST é necessário levar em conta fatores econômicos e políticos que tem início na década de 1970. O modelo econômico de desenvolvimento agropecuário implantado nos governos militares, denominado de modernização conservadora, visava acelerar a modernização da agricultura com base na grande propriedade, através da criação de um sistema de créditos e subsídios. Como consequiência dessa política houve o aumento das áreas de cultivos das monoculturas, aumento do trabalho assalariado, agravamento da situação da agricultura familiar, aumento da concentração de terras, expropriação e conseqüente expulsão de mais de 30 milhões de pessoas que migraram para as cidades ou outras regiões país (FERNANDES, 2000).

"A expropriação, a expulsão das famílias camponesas e a usurpação do território indígena geraram uma das condições que levaram à luta os camponeses que iriam realizar a ocupação de terra, que também inaugurou o

Geo UERJ - Ano 15, nº. 24, v. 1, $1^{\circ}$ semestre de 2013 p. 145-160

ISSN: $1415-7543$ E-ISSN: 1981-9021

http://www.e-publicacoes.uerj.br/index.php/geouerj 
processo de formação do MST, na região noroeste rio-grandense" (FERNANDES, 2000, p 50).

Ao abordar aspectos referentes às origens do Movimento e da luta pela terra, Medeiros (2004) explica que a abertura em direção à reforma agrária brasileira, teve suas origens na região do Alto Uruguai no Rio Grande do Sul. De acordo com a autora, os colonos que lá chegaram ao final do século XIX e princípio do século XX construíram cidades, desenvolveram regiões e não desistiram quando a modernização da agricultura chegou ao planalto gaúcho. Muitos deles procuraram novas alternativas de sobrevivência partindo para áreas distantes ou sendo atraídos para as cidades, porém os que permaneceram e lutaram pelo direito de ter acesso a terra se organizaram e criaram o Movimento dos Trabalhadores Sem Terra - MST.

Esse Movimento nascido de um processo de desterritorialização e luta pela sua reterritorialização teve como marco histórico o mês de maio de 1978 quando os índios Kaigang da Reserva Indígena de Nonoai iniciaram ações para recuperar seu território e expulsaram 1.800 famílias de colonos-rendeiros que viviam nas terras. Para estas famílias restava apenas três alternativas: migrar para os projetos de colonização da Amazônia, virar assalariadas em empresas agropecuárias ou de indústrias nas cidades ou lutar pela terra no Rio Grande do Sul. Como não havia uma organização, ocorreu a dispersão da maior parte das famílias que passaram a vagar pelos municípios da região noroeste do Estado, algumas acamparam na beira de estradas, outras em casas de parentes e muitas perambularam sem ter onde ficar. Após dois meses da expulsão, algumas famílias começaram as ocupações, mesmo sem uma organização, em glebas de terras públicas arrendadas a empresas privadas. Como resposta, o governo enviou o secretário da agricultura para cadastrar as família e convencer elas a retornarem as casas de parentes prometendo assentá-las quando houvesse reforma agrária. Contudo, além das famílias expulsas que ocupavam as áreas, surgiram mais famílias querendo se cadastrar, com esperança de serem assentadas (FERNANDES, 2000).

Devido a necessidade de mudanças e com o incentivo de um padre que trabalhava na Comissão Pastoral da Terra, as famílias de trabalhadores sem terra, decidiram se reunir, para se organizar e discutir as medidas a serem tomadas. Após uma audiência com o governador do estado do Rio Grande do Sul e a falta de resoluções para o problema, no dia 7 de setembro de 1979, 110 famílias ocuparam a Gleba Macali, no município de Geo UERJ - Ano 15, nº. 24, v. 1, $1^{\circ}$ semestre de 2013 p. 145-160 ISSN: 1415-7543 E-ISSN: 1981-9021 http://www.e-publicacoes.uerj.br/index.php/geouerj 
Nonoai. Após alguns dias da ocupação, pressionado o governador autorizou os colonos a plantarem na terra: "Iniciava a primeira experiência de organização do trabalho e da produção na terra conquistada" (FERNANDES, 2000, p.53).

A partir dessa experiência houve outras ocupações, como na Gleba Brilhante e ao mesmo tempo em que a luta pela terra conquistava mais apoio da sociedade, a repressão policial tornava-se mais intensa, como em outubro de 1980, na ocupação da Fazenda Annoni, com intervenção da Polícia Federal fazendo o despejo das famílias e prendendo doze trabalhadores. Já o caso do acampamento Encruzilhada Natalino, a luta pela terra representou o conflito entre a política implantada pelos militares e a política de desenvolvimento para a agropecuária que os camponeses vinham construindo por meio de suas lutas.

\footnotetext{
"Na luta pela terra, a encruzilhada também tem seu sentido de cruzamento dos caminhos construídos durante a resistência. Cruzam-se os caminhos da vitória e da derrota. A encruzilhada é o lugar e o momento da tomada de decisão para qual direção deve-se seguir, com o objetivo de conquistar a terra. É, portanto, um lugar onde se para, reflete e olha, procurando visualizar o melhor caminho a percorrer. E muitas vezes se o caminho não existe, é preciso fazê-lo. Foi assim que aconteceu na Encruzilhada Natalino, ali também foi o ponto de partida para a construção da luta pela terra" (FERNANDES, 2000, p. 55).
}

Percebe-se, através deste breve histórico, que uma das motivações da formação da organização de trabalhadores rurais sem terra no Rio Grande do Sul foi a resistência a deixar o seu Estado e a vida no campo. A resistência em deixar para trás o espaço de seu território desterritorializado, elemento de seu espaço de vida e parte da expressão de sua identidade.

O retorno a um antigo território, mesmo que de seus pais ou avós, representa também a busca da recriação de uma identidade, uma nova identidade campesina, daqueles que em determinado momento não optaram por resistir, e sim foram seduzidos pelas cidades, as mesmas que hoje os expulsa e lhes trás a necessidade de uma nova reterritorialização.

\section{TRABALHADORES URBANOS EM ASSENTAMENTOS RURAIS}

Conforme pudemos perceber ao longo da seção anterior, a luta pela terra é uma conseqüência histórica, que ocorre não apenas no estado do Rio Grande do Sul, mas

Geo UERJ - Ano 15, nº. 24, v. 1, $1^{\circ}$ semestre de 2013 p. 145-160

ISSN: $1415-7543$ E-ISSN: 1981-9021

http://www.e-publicacoes.uerj.br/index.php/geouerj 
também em todo território brasileiro. Os dados do DATALUTA (2010) demonstram que ao longo de pouco mais de 30 anos, cerca de 1.030.610 famílias foram assentadas em 8.823 assentamentos distribuídos ao longo do território nacional (Tabela 1).

Tabela 1 - Número de assentamentos rurais e famílias assentadas por

Macrorregiões - 1979-2010

\begin{tabular}{ccccc}
\hline Região & Assentamentos & \% & Famílias & \% \\
\hline Norte & 1.977 & 22 & 444.724 & 43 \\
Nordeste & 4.049 & 46 & 333.289 & 32 \\
Centro-Oeste & 1.203 & 14 & 161.120 & 16 \\
Sudeste & 787 & 9 & 51.637 & 5 \\
Sul & 807 & 9 & 39.840 & 4 \\
\hline Brasil & $\mathbf{8 . 8 2 3}$ & $\mathbf{1 0 0}$ & $\mathbf{1 . 0 3 0 . 6 1 0}$ & $\mathbf{1 0 0}$ \\
\hline
\end{tabular}

Fonte: DATALUTA, 2011.

Esses números demonstram a importância da temática e as proporções das conquistas da luta pelo acesso a terra no Brasil, com maiores expressões de assentamentos e famílias assentadas nas regiões Norte e Nordeste. Também, de acordo com os dados do DATALUTA (2011), o estado do Rio Grande do Sul, até o ano de 2010 contava com 331 assentamentos ocupados por 5.945 famílias.

Cada uma dessas famílias assentadas possui uma história na coletividade do Movimento, assim como uma história particular, calcada nos sucessivos processos de desterritorialização-reterritorialização. É nesse contexto, que a pesquisa aqui apresentada procura identificar o processo de territorialização de famílias assentadas em três assentamentos localizados na Campanha Gaúcha, dando enfoque especial para a marcante presença de pessoas oriundas de áreas urbanas em assentamentos rurais.

Dessa forma, foram realizadas entrevistas com informantes qualificados nos assentamentos Novo Horizonte II (Santa Margarida do Sul), Conquista do Caiboaté (São Gabriel) e Cerro dos Munhós (Santana do Livramento) (Figura 1).

Figura 1 - Localização dos Assentamentos visitados

Geo UERJ - Ano 15, no . 24, v. 1, $1^{\circ}$ semestre de 2013 p. 145-160 ISSN: $1415-7543$ E-ISSN: 1981-9021 http://www.e-publicacoes.uerj.br/index.php/geouerj 


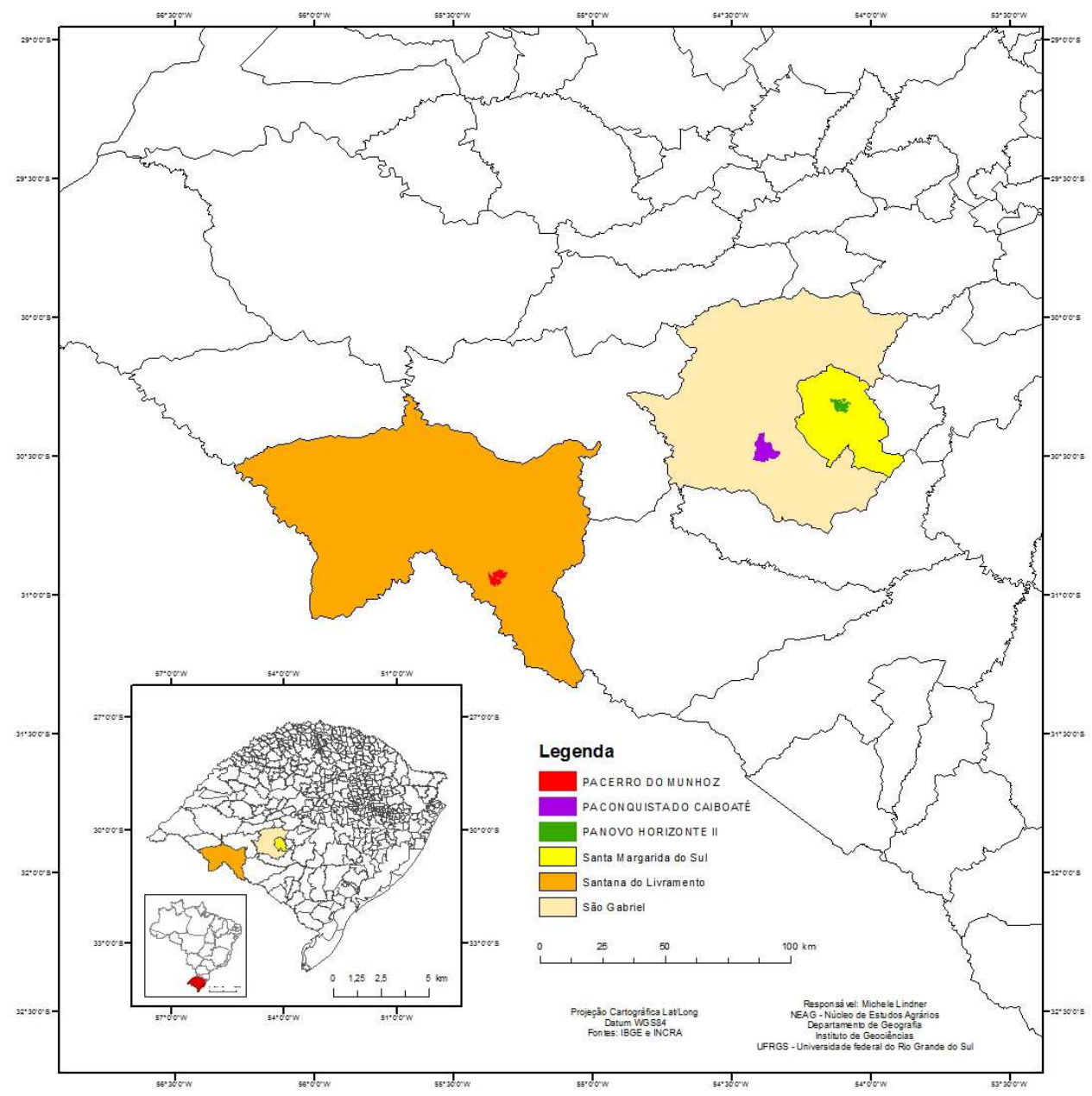

Esses informantes foram selecionados com base em uma amostra intencional, que segundo Almeida (1989, p.87), "consiste em selecionar um grupo de elementos considerados típicos em função das variáveis estudadas".

A escolha pela entrevista deu-se por esta representar uma técnica que trás mais liberdade, possibilitando assim, obter do entrevistado o que ele considera mais importante sobre determinados problemas, suas descrições de determinadas situações. Todas as entrevistas realizadas neste estudo foram entrevistas guiadas. Nesse tipo de entrevista, segundo Richardson (2008), o pesquisador conhece previamente os aspectos que deseja pesquisar e com base neles formula alguns pontos para tratar na entrevista. As perguntas dependem do entrevistador e o entrevistado tem a liberdade de expressarse como quiser guiado pelo entrevistador. Dessa forma, entre os diversos aspectos pesquisados, buscou-se saber dos entrevistados informações relativas à sua procedência Geo UERJ - Ano 15, nº. 24, v. 1, $1^{\circ}$ semestre de 2013 p. 145-160 ISSN: 1415-7543 E-ISSN: 1981-9021 http://www.e-publicacoes.uerj.br/index.php/geouerj 
e ocupação anterior, sua história antes de entrar no Movimento e as mudanças percebidas após serem assentados. Com base nessas informações pode-se identificar diversos aspectos dos processos de territorialização desses sujeitos.

Entre as questões levantadas com os assentados, uma chamou atenção especial e motivou o artigo em questão, a moradia e ocupação anterior à entrada no Movimento e assentamento. Durante as entrevistas, percebeu-se a forte presença de pessoas oriundas das cidades nos assentamentos, pessoas essas que ou nasceram e trabalharam na cidade ou em algum momento de suas vidas foram trabalhar ou morar nestas em busca de melhores condições de vida e posteriormente buscaram ou retornaram ao campo por este mesmo motivo.

Do total das entrevistas realizadas nos assentamentos, apenas dois sujeito declararam terem sido sempre agricultores, um deles informou ter residido sua vida toda na área rural, tendo entrado no Movimento e na luta pela terra devido a possuir uma área muito pequena para a reprodução socioeconômica de sua família e o outro declarou de ter sido trabalhador assalariado no campo. Os demais entrevistados declararam em determinado momento de suas vidas terem trabalhado ou residido na área urbana.

Entre os entrevistados de antecedência citadina, muitos deles possuíam raízes campesinas, como a infância no campo, pais ou avós agricultores, expressando a representação do êxodo rural, daqueles que devido à modernização da agricultura, o minifúndio, a exploração do trabalho assalariado no campo buscaram na cidade melhores condições de vida. A saída do campo em busca de melhores condições de vida pode ser percebida nas falas a seguir:

"Um belo dia olhei para os meus familiares, para aquelas pessoas que conviviam naquela situação e joguei o facão do lado e disse: to indo embora vou pro Rio de Janeiro, vou trabalha" (E.C.A. - Assentado, 33 anos).

"Eu tinha a ilusão que ia trabalhar na grande cidade, que eu ia melhorar de vida e ia ter uma situação melhor para ajudar minha mãe" (E.C.A. - Assentado, 33 anos).

Os trechos dos depoimentos do assentado expressam uma situação encontrada nos depoimentos de diversos outros assentados, a ilusão do desenvolvimento socioeconômico na cidade grande, com mais oportunidades de emprego e maior facilidade de acesso a bens e serviços. Contudo, ao longo dos depoimentos dos 
entrevistados pode-se perceber que a realidade encontrada na cidade foi uma realidade de exclusão que os levou a luta pela terra.

E.C.A. (33 anos), natural do Rio de Janeiro - RJ relatou que quando criança trabalhava com os pais e irmãos cortando cana-de-açúcar em uma fazenda. O trabalho era pesado e as condições de vida muito difíceis, pois não podiam plantar alimentos e nunca recebiam o pagamento em dinheiro. O Assentado descreve a situação que a família se encontrava da seguinte forma: "a fazenda era um quartel fechado, lá tinha a agroindústria, o comércio que era dela e tinha as casinhas onde colocavam as famílias ali para trabalhar para eles. Ai tu tinha que trabalhar para cortar cana, comprava a alimentação na venda deles, tu era meio que escravo, não podia planta nada". A partir disso, relata que decidiu "mudar de vida" e buscar trabalho na "cidade grande". Porém, as condições de vida na cidade não foram muito diferentes, trabalhou durante algum tempo descarregando caminhões de frutas e legumes e depois arrumou emprego em um restaurante onde permaneceu por cerca de sete anos, até entrar no Movimento e na luta pela terra.

Em outra entrevista, o assentado I.V. (30 anos), natural de Chapecó - SC relata que até os 16 anos trabalhou na roça com o pai, em uma propriedade de cerca de dois hectares e meio. Compondo uma família de sete irmãos, mudou-se para a cidade em busca de trabalho, pois a vida no campo se tornara insustentável. Na cidade trabalhou durante cerca de dez anos na construção civil, emprego esse, que segundo o informante representou na época a "única opção", na qual permaneceu até surgir um acampamento do MST próximo ao local onde morava, deixando assim o emprego e juntando-se ao acampamento.

A.A.M.S. (29 anos), também informou ter residido e trabalhado no campo quando criança ajudando seu pai. $\mathrm{O}$ assentado relata que a vida na cidade foi muito difícil devido à falta de oportunidades de trabalho, sendo necessário trabalhar com "serviços gerais", não apenas na cidade, mas também no campo. Em determinado momento de sua vida teve a oportunidade de realizar alguns serviços em um assentamento e foi então que conheceu o Movimento e passou a participar em busca de "uma terra".

A assentada J.B.F.P. (46 anos), possui uma história um pouco diferente das demais. De origem citadina, seu contato com o campo se dava devido a ser neta de agricultores.

Geo UERJ - Ano 15, nº. 24, v. 1, $1^{\circ}$ semestre de 2013 p. 145-160

ISSN: $1415-7543$ E-ISSN: 1981-9021

http://www.e-publicacoes.uerj.br/index.php/geouerj 
Pedagoga de profissão trabalhava na cidade como professora e julgava que seu trabalho não era devidamente reconhecido no local. Através de amigos entrou no Movimento, trabalhando na formação educacional e integrando a luta pela terra.

De outra forma, o assentado M.T. (26 anos), também possui uma história um pouco diferenciada das demais, tendo entrado na luta pela terra e se integrado ao Movimento após ter realizado um curso de graduação voltado para a Agricultura Familiar. Porém, sua ligação com o campo vai além de sua formação, o assentado natural de Arroio do Tigre - RS relatou que quando criança ajudava nas lidas do campo até a família ter que deixar a propriedade rural onde residia para seu pai trabalhar na cidade.

Ao prestarmos atenção nesses breves relatos que exemplificam uma realidade muito encontrada em assentamentos na Campanha Gaúcha, percebemos diversos pontos em comum norteados pela fuga da pobreza urbana e a busca de uma melhor qualidade de vida no campo, através da luta pelo acesso a terra, a Luta que expressa o processo de desterritorialização e reterritorialização desses sujeitos. Contudo, o processo da territorialização, a formação da "nova" identidade campesina dos assentados, também é percebida nas comparações através de expressões retiradas das falas dos sujeitos entrevistados que qualificam do seu "antigo" lugar e seu "novo" lugar (Tabela 2).

Tabela 2 - Qualificações relativas aos territórios dos assentados

\begin{tabular}{cc}
\hline "Antigo" lugar & "Novo" lugar \\
\hline Insustentável & Autonomia \\
Relação de peão & Liberdade \\
Ilusão & Relação de patrão \\
Lugar que não era seu & Maior nível de vida \\
& Auto-sustento \\
& Lugar para morar \\
& Ambiente melhor \\
& Qualidade de vida \\
& Conquista \\
\hline
\end{tabular}

Fonte: Pesquisa de campo, 2012.

Geo UERJ - Ano 15, nº. 24, v. 1, $1^{\circ}$ semestre de 2013 p. 145-160

ISSN: $1415-7543$ E-ISSN: 1981-9021

http://www.e-publicacoes.uerj.br/index.php/geouerj 
Com base nas qualificações pode-se perceber claramente que o processo de territorialização no "novo" lugar tem um significado de conquista e melhoria da qualidade de vida, traduzido por ter um lugar que é seu, por ter onde morar, ter onde produzir com liberdade e autonomia. Portanto, a formação de uma "nova" identidade campesina se vislumbra nessa luta, a luta pelo acesso a terra, a luta pelo seu território, ou seja, todo esse processo de territorialização, que envolve desterritorializações e reterritorializações e está claramente impresso na fala do assentado que encerra essa seção.

"Antes eu não tinha lugar, hoje eu tenho um lugar para morar" (E.C.A. - Assentado, 33 anos).

\section{CONSIDERAÇÕES FINAIS}

Há tempos já percebemos que a luta pela terra deixou de ser exclusividade de camponeses expulsos de suas terras e de proprietários de minifúndios lutando pela sua sobrevivência no campo. A pobreza urbana se junta à luta pela terra em busca de melhorias na qualidade de vida e reflete o retorno da valorização da vida campesina, através da representação de uma alternativa de reterritorialização para pessoas que de alguma forma se sentiram excluídas nas cidades.

Nos últimos anos percebe-se claramente o aumento da presença de trabalhadores urbanos no Movimento dos Trabalhadores Sem Terra (MST) como demonstra a pesquisa aqui apresentada. Enquanto em assentamentos mais antigos se percebe maior presença de assentados de origem rural, aqueles que nunca deixaram o campo e que quando tiveram que deixar suas propriedades ingressaram na luta pela terra, nos assentamentos mais recentes é fortemente perceptível a presença de assentados vindos de áreas urbanas. Muitos destes são pessoas de origem rural, que em determinado momento de suas vidas acreditaram que a cidade poderia lhes trazer melhores oportunidades de trabalho e renda, e por essa motivação foram atraídas para estes espaços.

Sabe-se que a modernização da agricultura, gerou efeitos perversos de ordens sociais e ambientais, como o aumento das áreas de monoculturas, maior concentração de terras e utilização de insumos, aumento da mecanização no campo e a conseqüente diminuição

Geo UERJ - Ano 15, nº. 24, v. 1, $1^{\circ}$ semestre de 2013 p. 145-160 ISSN: 1415-7543 E-ISSN: 1981-9021 http://www.e-publicacoes.uerj.br/index.php/geouerj 
da força de trabalho humano. Esses aspectos, aliados a inviabilidade econômica de pequenos produtores que tiveram que abandonar suas propriedades por não terem condições de se adaptar a nova realidade imposta através de políticas governamentais, levaram ao fenômeno muito conhecido, chamado êxodo rural.

Nesse contexto, conforme demonstra a pesquisa, os filhos e netos do êxodo rural, e até mesmo os que vivenciaram diretamente esse processo, muitas vezes acabam retornando ao campo pelo mesmo motivo que um dia o deixaram. A cidade que um dia os acolheu e representou sinônimo de desenvolvimento, passa a expulsa-los e os excluí-los, mostrando como alternativa um rural com mais opções de sobrevivência e qualidade de vida.

Portanto, o que se buscou chamar a atenção nesse artigo foi justamente esse processo de territorialização enfrentado por esses indivíduos em busca de seu território. O campo que um dia expulsou (desterritorializou) volta a acolher (reterritorizar), transformando a relação do individuo com o espaço, formando uma nova identidade a partir da reterritorialização campesina.

\section{REFERENCIAS BIBLIOGRÁFICAS}

ALMEIDA, J. A. Pesquisa em extensão rural: um manual de metodologia. Brasília: MEC/ABEAS, 1989.

DATALUTA - Banco de Dados da Luta pela Terra. FELICIANO, Carlos Alberto (Coord.). Relatório 2010. Presidente Prudente, SP: NERA - Núcleo de Estudos, Pesquisas e Projetos de Reforma Agrária - FCT/ UNESP, 2011.

FERNANDES, Bernardo Mançano. A formação do MST no Brasil. Petrópolis, RJ: Vozes, 2000.

HAESBAERT, Rogério (Rogério Haesbaert da Costa). O mito da desterritorialização: do "fim dos territórios" à multiterritorialidade. Rio de Janeiro. Bertrand Brasil, 2004.

MEDEIROS, Rosa Maria Vieira. O Rio Grande do Sul e a busca pela Reforma Agrária. In: VERDUM, Roberto; Basso, Luis Alberto; SUERTEGARAY, Dirce Maria Antunes (Orgs.). Rio Grande do Sul: paisagens e territórios em transformação. Porto Alegre: Editora da UFRGS, 2004.

Geo UERJ - Ano $15, \mathrm{n}^{\circ} .24$, v. $1,1^{\circ}$ semestre de 2013 p. 145-160 ISSN: $1415-7543$ E-ISSN: 1981-9021 http://www.e-publicacoes.uerj.br/index.php/geouerj 
. RE-TERRITORIALIZAÇÃO E IDENTIDADE. O SIGNIFICADO DOS ASSENTAMENTOS PARA A ECONOMIA DOS MUNICÍPIOS: os casos de hulha Negra, Aceguá e Candiota na Campanha Gaúcha (RS). IX Coloquio Internacional de Geocrítica. LOS PROBLEMAS DEL MUNDO ACTUAL. SOLUCIONES Y ALTERNATIVAS DESDE LA GEOGRAFÍA Y LAS CIENCIAS SOCIALES. Porto Alegre, 2007.

RAFFESTIN, Claude. Por uma geografia do poder. São Paulo: Editora Àtica, 2011.

RICHARDSON, R. J. Pesquisa Social: métodos e técnicas. 3 ed. São Paulo: Atlas, 2008.

SAQUET, Marcos Aurelio. Reterritorialização e identidade. In: MEDEIROS, Rosa Maria Vieira; FALCADE, Ivanira (Orgs.). Tradição versus tecnologia: as novas territorialidades do espaço agrário brasileiro. Porto Alegre: Editora da UFRGS, 2009. Artigo recebido para publicação em outubro de 2012.

Artigo aceito para publicação em maio de 2013. 